\title{
A TEORIA DE REDE E A ARQUEOLOGIA DA HISTÓRIA MODERNA*
}

\author{
Charles E. Orser Jr.**
}

\section{Introdução}

Em meu livro A Historical Archaeology of the Modern World (Orser 1996), esbocei, de maneira geral, uma perspectiva de abordagem que buscava dar forma a uma possível Arqueologia Histórica global. $\mathrm{O}$ foco de meu argumento era que, por volta do ano 1500 d.C., agentes conscientes do colonialismo, do capitalismo, do eurocentrismo e da modernidade haviam criado uma série de elos complexos e multidimensionais que uniam diversos povos ao redor do globo. Argumentava, de maneira sucinta, que se devia à interação desses diversos povos as várias manifestações históricas do mundo moderno - mundo o qual habitamos. A idéia de que homens e mulheres, no decurso de suas vidas quotidianas, criam e mantêm determinadas conexões que tanto promovem a mudança quanto legitimam a continuidade cultural ao longo do tempo, era central para minha argumentação.

Defendi naquela ocasião, então, que a Arqueologia Histórica, para ter um lugar significativo na produção acadêmica cotidiana, deveria levar em consideração a questão das interligações globais, fornecendo estudos empíricos que demonstrassem a origem e os desenvolvimentos ulteriores da globalização, da modernização e da expansão colonialista. Ainda acredito na validade essencial de meu programa geral de pesquisa (Orser 1998c, a ser publicado), mas, tendo então esboçado apenas uma abordagem geral dele, é agora apropriado desenvolver uma estrutura concreta que guie a espécie de estudos arqueológicos que eu defendo. Acredito que meus objetivos de pesquisa podem lograr melhores resultados ao optar-se por uma abordagem, en-

(*) Traduzido por Fábio Adriano Hering e revisado por Pedro Paulo A. Funari.

$\left(^{* *}\right)$ Antropologia, Universidade Estadual de Illinois, EUA. tre as várias que podem ser selecionadas ou desenvolvidas, que tenha suas raízes mais profundas na análise de rede desenvolvida a partir da Antropologia e da Sociologia contemporâneas, assim como da Geografia. O propósito deste artigo é apresentar um esboço dessa abordagem, argumentando em favor de suas possibilidades e pótencialidades interpretativas. O uso de tal abordagem, como creio, possibilitará aos estudiosos da Arqueologia Histórica coletar, avaliar e interpretar seus dados de novas e profícuas maneiras. Como parte de minha argumentação, apresento, também, um breve exemplo do Brasil do século XVII, mais especificamente do reino escravo de Palmares.

\section{Um princípio central e suas implicações}

Um pressuposto central da espécie de análise que proponho repousa sobre a proposta de que homens e mulheres mantêm-se unidos socialmente por meio de uma série de complexas inter-relações que podem ser modeladas como uma teia. Esta compreensão da sociedade humana tem uma longa genealogia no pensamento antropológico. Por exemplo, no início do século $\mathrm{XX}$, o cientista social Emile Durkheim (1915: 426) propôs que as unidades sociais, usualmente identificadas pelos analistas como sendo estreitamente limitadas, ou como entidades isoladas, eram, na verdade, unidades amplas e de longo alcance. Como ele mesmo afirmou: "Não existe pessoa ou estado que não seja parte de outra sociedade, mais ou menos ilimitada, que abarque todas as pessoas e todos os estados com os quais ela inicialmente tomou contato, seja direta ou indiretamente" $O$ tema da interligação foi posteriormente adotado tanto pelo antropólogo britânico A. R. Radcliffe-Brown (1940) quanto pelo antropólogo americano Alexander Lesser (1961). Ambos seguiram as idéịas de Durkheim, 
ORSER Jr., C.E. A teoria de rede e a Arqueologia da História Moderna. Rev. do Museu de Arqueologia e Etnologia, São Paulo, Suplemento 3: 87-101, 1999.

centrando suas atenções na noção de rede social. Radcliffe-Brown (1940: 3) escreveu que todo indivíduo era parte de "uma imensa rede de relações sociais, na qual estavam envolvidas várias outras pessoas". e Lesser (1961: 42) argumentou que os grupos humanos estavam "inextrincavelmente envolvidos com outros agregados, próximos e distantes, em associações que se assemelham a redes ou teias". Ao longo desse período, outros cientistas sociais adotaram o conceito de teia social para desenvolver uma explícita "análise de rede social" $\mathrm{Na}$ Antropologia, J. A. Barnes (1954) e J. C. Mitchell (1974) foram pioneiros no desenvolvimento de tais abordagens, e, hoje, um campo francamente aberto à análise de rede social existe tanto na Antropologia quanto na Sociologia (Wasserman e Faust 1994). Mais recentemente, o antropólogo Michael Carrithers (1992: 11) tem usado o termo mutualismo para se referir à idéia de que as relações sociais são "o material básico da vida humana"

Seguindo a trilha aberta pelo estudo pioneiro de Barnes (1954), no qual esse autor estuda as redes sociais criadas e em atividade em uma pequena vila pesqueira norueguesa, um número de pesquisadores refinou e ampliou a idéia de rede social, tentando descobrir: como redes operam; como redes são construídas; como homens e mulheres assim como outros grupos sociais coletivos - produzem e reproduzem os elos que os unem. Pesquisas posteriores têm mostrado, por exemplo, que tais ligações podem incluir uma ampla variedade de fatores: laços de família, lealdades e percepções de classe, percepç̧ões ambientais, estratégias econômicas, relações de poder e percepções cognitivas (Knole e Kuklinski 1982: 15; Schweizer 1997; Wolf 1982, 1984).

Uma das implicações de se adotar uma perspectiva de rede é que ela permite ao investigador atenuar os misteriosos efeitos da cultura. Em um ponto de vista puramente "culturalista", os indivíduos fazem coisas por causa de sua cultura. A cultura parece flutuar por sobre eles como uma nuvem etérea, invisível ainda que presente, inelutavelmente exercendo seu poder por sobre tudo o que as pessoas fazem. A perspectiva culturalista ajuda a explicar, por exemplo, como os colonizadores podem mover-se de uma parte a outra do mundo e criar uma imagem de sua terra natal, em um diferente meio ambiente.

Explicações culturalistas têm sido particularmente dominantes na Arqueologia, especialmente na Arqueologia Histórica. Os arqueológos que estudam o colonialismo posterior a Colombo têm incorporado paradigmas culturalistas graças à aparente capacidade que tais paradigmas têm de explicar a transferência de uma cultura de um lugar para outro. De acordo com essa perspectiva, James Deetz, um reconhecido profissional da área, tem concedido a essa perspectiva um lugar de proeminência no aparato interpretativo da Arqueologia Histórica. Conseqüentemente, para ele, uma "paisagem cultural" é "aquela parte do terreno que é modificada de acordo com um grupo de planos culturais" (Deetz 1990: 2). Dentro dessa compreensão, paisagens construídas pelo homem parecem ser como são por causa da cultura. As pessoas dão forma a suas paisagens materiais de acordo com o que as torna confortáveis para elas. Em situações coloniais, então, a transferência da cultura, de uma parte do mundo para outra, tem sido interpretada, literalmente, a partir de uma perspectiva que propõe que: "Na extremidade meridional do continente africano, tem-se um pequeno pedaço da Inglaterra" (Deetz 1990: 1). Dado que os homens e as mulheres que viajam pelo globo carregam consigo suas culturas, tem sentido o fato de que tais pessoas construirão meio-ambientes que se encaixem com seus modelos cognitivos, de acordo com o que elas compreendem como certo e errado. Dessa maneira, a perspectiva culturalista explica, a partir da comparação com uma rede, por que existem estruturas similares em diferentes partes do mundo. O Fort Orange (Forte Orange), no estado de Nova Iorque, por exemplo, assemelha-se à Fortaleza de Santa Cruz do Itamaracá, no nordeste do Brasil, pois foi a Coroa holandesa que construiu ambas as fortificações. Os construtores e engenheiros de ambos os fortes, obviamente, erigiram estruturas que, de acordo com suas compreensões culturais, representavam apropriadamente um lugar fortificado. Outra maneira de dizer isso é que os construtores dos fortes, com efeito, viviam sob uma influência difusa de sua cultura; um fato que os objetos materiais por eles construídos parecem refletir extremamente bem.

A concepção culturalista da paisagem cultural parece fazer bastante sentido e muitos estudiosos da Arqueologia Histórica têm usado esse modelo em suas pesquisas (vide, por exemplo, os artigos em Kelso e Most 1990, e Yamin e Metheny 1996). Muitos arqueólogos, treinados na tradição antropológica, sentem-se à vontade em usar a cul- 
ORSER Jr., C.E. A teoria de rede e a Arqueologia da História Moderna. Rev. do Museu de Arqueologia e Etnologia, São Paulo, Suplemento 3: 87-101, 1999.

tura como a explicação final para compreender as maneiras através das quais o mundo funciona. $\mathrm{O}$ meio ambiente construído, como quase todo o resto, reflete a cultura. Essa conclusão é, talvez, em alguma medida, adequada, mas será suficiente? Mesmo Deetz (1991: 8) disse que a Arqueologia Histórica deveria com frequiência refutar a Espada de Occam, ${ }^{1}$ querendo dizer, é claro, que a explicação mais simples pode não ser sempre a melhor. Tal é o caso com a explicação culturalista.

A opção culturalista tem, sem dúvida, encontrado uma audiência atenta entre vários profissionais da Arqueologia Histórica, mas ela apresenta dois problemas que não podem ser ignorados. Em primeiro lugar, tal opção incorpora uma vaga noção de cultura, dando-lhe poder explicativo. Muitos arqueólogos são, sem dúvida, acadêmicos cuidadosos, mas a opção culturalista torna muito fácil concluir uma investigação de maneira simplista, por meio de uma "explicação" culturalista do tipo: "Sua cultura fez com que eles fizessem isso". Em outras palavras, o ponto de vista culturalista propõe explicações e interpretações por demais simplistas para dar conta, por exemplo, de situações históricas extremamente complexas. A apresentação de interpretações simplistas não contribui para a profissão arqueológica, especialmente em uma época na qual os financiamentos para projetos arqueológicos correm o risco de serem reduzidos ou de desaparecerem por completo. A segunda deficiência da perspectiva culturalista é que ela tende a desprezar ou mesmo esconder relações sociais mutáveis, históricas, criando nesse vazio pinturas aparentemente sincrônicas do passado. Dessa maneira, um culturalista pode pretender que uma paisagem construída pelo homem represente um distintivo cultural, enquanto, de fato, tal paisagem repousa por muitos anos como que congelada no tempo. Da mesma maneira, quando os membros da sociedade utópica Harmony Society criaram sua "paisagem cultural" em Economy, Pennsylvania,

(1) A Espada de Occam é um princípio lógico, freqüentemente denominado de princípio da parcimônia, atribuído a Guilherme de Occam. Tal princípio sustenta que, ao se analisar uma questão, não se deve fazer mais pressuposições do que o mínimo necessário. Desde a Idade Média, esse princípio tem desempenhado um papel de destaque, servindo a teóricos e lógicos que buscam eliminar elementos fictícios ou desnecessários de suas explicações e de suas argumentações (n.t.). isto "simbolizava a terra natal da Alemanha, da qual eles foram forçados a fugir" (De Cunzo et al. 1996: 111). Enquanto que nenhum arqueólogo, desconsiderando o interesse particular de cada um, é desatento em relação à mudança diacrônica, a perspectiva culturalista, por outra parte, torna possível, e até fácil, aceitar algum grau de sincronicidade. Os alemães criaram uma pequena Alemanha na Pennsylvania, como que parada no tempo. Esta afirmação é, em alguma medida, verdadeira. Entretanto, de maneira geral, é difícil modelar internamente a mudança cultural de uma paisagem, quando ela, como um todo, é vista como uma criação cultural.

Uma abordagem de rede rejeita de maneira franca a posição culturalista e propõe, em seu lugar, que paisagens sejam compreendidas como criações conscientes, baseadas não estritamente na cultura mas nas interações e associações de agentes masculinos e femininos. As associações e relações de um indivíduo são criações conscientes que estão livres para mudar de acordo com a situação. Em se tratando de um lugar físico, material, ao invés de uma paisagem cultural - um espaço criado pelos caprichos da cultura -, a abordagem de rede entende que as criações físicas, materiais, requerem, para que se as compreenda, um íntimo conhecimento do tempo e do espaço. Para que tal conhecimento seja construído, deve-se levar em consideração duas dimensões interconexas, as estruturas sócio-históricas e sócio-ambientais. Essas estruturas são compostas de relações "ser humano para com ser humano" e "ser humano para com meio ambiente". Se quisermos, podemos nos referir a essas estruturas como culturais, mas apenas de uma forma denominativa; o uso de "cultura" nesse exemplo, entretanto, não tem qualquer finalidade e potencialidade explicativas.

\section{Análises de rede no passado da Arqueologia}

O interesse nos usos que o passado fez do espaço não é novo na Arqueologia. Começando com os estudos de assentamentos pioneiros de Willey (1953), no Peru, os arqueólogos têm considerado e avaliado onde antigas pessoas construíram seus sítios e monumentos; muitos arqueólogos, nesse sentido, têm desenvolvido análises espaciais ou locacionais, na tentativa de explicar antigas distribuições de sítios (vide, por exemplo, Clarke 1977a; 
Hodder e Orton 1976; Kent 1984;Zimmerman 1977). Tem emergido desses estudos, assim como daqueles desenvolvidos por acadêmicos de outros campos, a noção de que o lugar onde as coisas não estão é tão importante como aquele onde elas estão. Embora os arqueólogos, necessariamente, centrem suas escavações nos lugares singulares onde as atividades do passado ocorreram - onde as coisas estão - eles também compreendem a importância do lugar onde as coisas não estão. Um exemplo clássico pode ser encontrado na Esfera de Interação Hopewell, um modelo que propõe que os indivíduos das comunidades pré-históricas do MeioOeste dos Estados Unidos (de aproximadamente 100 a.C. a 300-350 d.C.) desenvolveram atividades econômicas em uma série de extensas redes. As redes em operação incluíam manifestações intralocais e interlocais, intra-regionais e inter-regionais, e mesmo manifestações trans-regionais, que, eventualmente, ligavam sítios separados entre si por centenas de quilômetros (Struever 1964; Struever e Houart 1972). Esse modelo foi criado para dar uma explicação para a presença de artefatos similares, que foram encontrados separados entre si por grandes distâncias. Entretanto, os criadores desse modelo tinham uma compreensão intuitiva de que tais objetos se moviam através do espaço com o propósito de que fossem depositados no lugar onde eles foram encontrados. Em outras palavras, com o propósito de alcançar seu lugar de repouso definitivo, os artefatos tinham, necessariamente, de ter ocupado uma série de diferentes posições ao longo de sua rota.

A necessidade que os arqueólogos têm de entender as interligações entre espaço e lugar foi percebida, de maneira explícita, alguns anos atrás, por David Clarke (1977b), que descreveu o que ele denominou "Arqueologia espacial" Como ele a definiu, Arqueologia espacial é:

“(...) a retirada de informação das relações arqueológicas espaciais e o estudo das consequiências espaciais dos padrões de atividade dos antigos hominídios dentro e entre estruturas, assim como as articulações de tais informações, dentro dos sítios, dos sistemas de sítio e dos seus meio ambientes: o estudo do fluxo e integração de atividades dentro $e$ entre as estruturas e os espaços de recurso a partir de uma escala micro para escalas semi micro e macro de agregação" (Clarke 1977: 9; ênfase do autor).
O uso sensivelmente datado que Clarke faz das estruturas totalizadoras dos níveis micro (dentro das estruturas) e macro (entre sítios) pode ser desculpado, mas sua compreensão básica é, de forma geral, coerente com a abordagem de rede que defendo. Clarke explicitamente compreendeu a diferença entre "Arquelogia espacial" - como uma tentativa de compreender a relevância de lugares e espaços - e uma Arqueologia de assentamento compreendida como uma Arqueologia que estuda lugares com vida humana. Uma Arqueologia que busque compreender as redes do passado tem muitas similaridades com a Arqueologia espacial de Clarke, com a exceção de que a minha abordagem dá muito mais ênfase à teoria social de rede, um assunto não tão bem formulado vinte anos atrás como é hoje. Embora Clarke não tenha feito nenhum uso detalhado da teoria de rede, mesmo quando ela foi então formulada (Haggett e Chorley 1969), ele, entretanto, tinha um surpreendente interesse em compreender as redes na pesquisa arqueológica (Clarke 1968: 469-72).

Exemplos que mostrem a importância das redes sociais nas análises da Arqueologia Histórica não são predominantes, mas eles de fato existem (Orser 1998b). Dois estudos derivados de pesquisas recentes em Annapolis, Maryland, demonstram isso (Shackel, Mullins e Warner 1998). No primeiro exemplo, Mark Warner (1998) investiga duas casas habitadas por famílias afro-americanas, no final do século XIX e começo do XX. Examinando a posição social e sua identificação com os artefatos - um tópico recorrente em Arqueologia Histórica - Warner observa que as comunidades afro-americanas não representavam uma comunidade monolítica. Ao contrário, os moradores da comunidade pareciam fazer escolhas conscientes a partir do que lhes era cobrado socialmente e do que era significativo de acordo com a situação. Os indivíduos, nessa perspectiva, tomam certas atitudes dentro de suas comunidades, não porque suas culturas façam-nos agir dessa maneira, mas porque algumas oportunidades determinadas pela situação se apresentaram a eles naquele momento. Warner usa o consumo de chá como um exemplo, mostrando como alguns afro-americanos, de maneira consciente, assimilaram o hábito de beber chá como uma estratégia para produzir benefícios sociais diretos. Homens e mulheres bebiam chá, não porque beber chá fosse alguma espécie de marca cultural, mas porque seu consumo promovia e man- 
ORSER Jr., C.E. A teoria de rede e a Arqueologia da História Moderna. Rev. do Museu de Arqueologia e Etnologia, São Paulo, Suplemento 3: 87-101, 1999.

tinha certos relacionamentos; relacionamentos que os consumidores de chá consideravam de grande valia em situações específicas. $O$ chá, em essência, então, ajudava a criar e manter certas ligações sociais pretendidas. Na Annapolis histórica, então, existiram diferentes redes de consumidores de chá. Uma das implicações dessa descoberta é que a presença de chícaras e pires de chá nos sítios, associados com os afro-americanos, serviu não para indicar a operação de alguma norma cultural, mas uma possível estratégia social de homens e mulheres reais que viveram naquela época e naquele lugar. Em outro estudo, Christopher Matthews (1998) mostra que um dos estilos arquitetônicos mais importantes da elite de Annapolis eram aqueles inspirados por Andrea Palladio. Matthews argumenta que, levando-se em consideração o fato de ele ter exercido um importante papel como criador, promovendo significativas intervenções no meioambiente da cidade de Chesapeake, devemos compreender o homem Palladio antes de começarmos a compreender seu estilo arquitetônico. Como parte dessa compreensão, devemos reconhecer que Palladio e outros arquitetos proeminentes projetaram construções que, em uma certa medida, eram idiossincráticas. Embora possamos supor que as construções fossem idiossincráticas de maneiras não muito culturalmente embaraçosas, é difícil argumentar que os arquitetos produziram construções simplesmente como produtos de sua cultura. A arquitetura palladiana é claramente européia na forma, mas o uso da perspectiva culturalista aqui, como uma ferramenta explicativa, de fato é satisfatório? Ao contrário, parece muito mais interessante e potencialmente muito mais esclarecedor argumentar que as construções projetadas pelos arquitetos acadêmicos buscavam tanto simbolizar, criar e manter relações sociais entre pessoas, quanto criar fronteiras entre indivíduos (vide também Leone 1995; Leone, Stabler e Burlaga 1998). Como objetos de grande dimensão que buscam comunicar mensagens complexas, as construções e os criadores por detrás delas - são elementos integrais das redes sociais. Eles buscam criar uma distância física e social entre homens e mulheres reais. Em ambos os exemplos, então, uma interpretação culturalista tanto não fornecerá explicações satisfatórias quanto não promoverá uma compreensão histórica. Creio que interpretações muito mais interessantes e profícuas serão obtidas a partir da adoção de uma explícita perspectiva de rede.

\section{Situando as análises de rede no pensamento arqueológico}

Logicamente, para que a teoria de rede se torne uma ferramenta útil para a interpretação arqueológica, os arqueólogos devem desenvolver quadros interpretativos que tenham alguma relevância arqueológica direta. Embora tentativas anteriores, por parte dos estudiosos da Pré-História, de adotar abordagens de rede em suas pesquisas, tenham sido desenvolvidas amplamente a partir de modelos oriundos da Geografia, o uso do registro escrito e do testemunho oral pelos estudiosos da Arqueologia Histórica tem tornado possível aplicar algumas das abordagens da teoria de rede social para os estudos da História posterior a Colombo.

As relações em atividade em um local sóciohistórico - englobando tanto relações "ser humano para com ser humano" quanto relações "ser humano para com meio ambiente" - pressupõem a existência de redes. Redes são facilmente conceituadas como gráficos compostos de pontos conectados por linhas. Em uma análise de rede formal, os pontos são denominados de "nós" ou "vértices" e as linhas que os conectam são denominadas "elos" ou "limites" (Haggett e Chorley 1969: 5; Wasserman e Faust 1994: 93). O trabalho do arqueólogo é descobrir a natureza e a composição dessas relações, aprender como elas foram expressas em termos materiais, e compreender essas expressões através do tempo. A primeira tarefa do arqueólogo é desenvolver uma compreensão conceitual dessas espécies de relações, reconhecendo o significado de suas manifestações históricas, e aceitando que uma estrutura criada para um local sócio-histórico não tem uma aplicação universal.

Para a análise arqueológica, é importante lembrar que relações "ser humano para com ser humano" assim como relações "ser humano para com meio ambiente" são, ao mesmo tempo, sociais e espaciais. É necessário também compreender que muitas das relações que os arqueólogos estudam deverão, de alguma forma, incorporar a noção de poder. Esta compreensão é particularmente pertinente para os estudiosos da Arqueologia Histórica pois as sociedades que eles estudam são, usualmente, de natureza capitalista, ou, ao menos, têm algum envolvimento (voluntário ou involuntário) com o empreendimento capitalista.

As relações capitalistas, necessariamente, pressupõem relações de poder. Embora possa ser mais 
ORSER Jr., C.E. A teoria de rede e a Arqueologia da História Moderna. Rev. do Museu de Arqueologia e Etnologia, São Paulo, Suplemento 3: 87-101, 1999.

fácil conceituar a ação das relações de poder entre indivíduos, podemos também observar, de nosso posto avançado de observação no século $\mathrm{XX}$ - em vista da destruição de diversas comunidades de seres vivos - que o poder é também exercido pelos seres humanos sobre comunidades animais e vegetais (Mander 1996). Conseqüentemente, tanto em relações "ser humano para com ser humano" como "ser humano para com meio ambiente". devemos aceitar a afirmação de Foucault de que "o espaço é fundamental em qualquer exercício de poder" (Rabinow 1984: 252). Onde existe espaço, particularmente em um contexto capitalista, existe também poder. Assim, a conduta própria do capitalismo é, necessariamente, tanto uma busca por espaço quanto um empreendimento social e econômico (Scott 1998; Sheppard e Barnes 1990).

Ao se introduzir as relações de poder, surge, necessariamente, a questão da ideologia. A ideologia tem sido, e muito provavelmente continuará sendo, um tópico acaloradamente debatido pelos estudiosos. Para o propósito deste artigo - dado que não é minha intenção levantar uma longa discussão a respeito da ideologia - será suficiente utilizar a compreensão clássica de ideologia, como algo que serve tanto para representar de maneira equivocada quanto para esconder as diversas relações entre homens e mulheres, compreendidos seja individual ou coletivamente. Ao invés de constituir uma força imutável exercida por uma classe sobre outra, os analistas mais sofisticados imaginam que as ideologias estão constantemente sendo redefinidas, tanto de acordo com o contexto histórico quanto de acordo com a localização, pelos reais atores históricos. Muitos acadêmicos, hoje, também aceitam que ideologias não são criadas unicamente pelas elites sociais, preferindo, em contrapartida, argumentar que toda unidade social é livre para construir e promover suas próprias ideologias. Dada esta realidade, é pertinente considerar as características e as consequiências do choque de ideologias dentro de uma sociedade. Para os estudiosos da Arqueologia Histórica, esse choque, usualmente, ocorre dentro de uma sociedade capitalista, ou em situações onde o capitalismo está sendo introduzido e ativamente promovido, esteja sendo aceito ou sofrendo resistência (Orser 1996: 16078). Desta maneira, compreender o choque de ideologias historicamente construídas em contextos capitalistas, necessariamente incorpora algum conhecimento de como relações de poder são criadas, pos- tas em ação e mantidas dentro de uma complexa teia de interação.

Relações sociais, relações de poder e a construção de ideologias são importantes tópicos arqueológicos, pois cada um deles sempre está associado a um lugar particular e a um certo tempo histórico. Dada a natureza da pesquisa arqueológica, as manifestações históricas de tais relações podem ser avaliadas através do tempo. Porém, antes que possamos levar a termo tais estudos diacrônicos, devemos definir um método e uma terminologia para compreender as características sincrônicas das próprias análises de rede. Tais análises de rede, teoricamente modeladas, devem ter relações profundas com as realidades sociais e históricas do contexto a ser investigado.

Como um primeiro passo, podemos dizer que os lugares onde se dá expressão às ligações sociais são "lugares", enquanto que a distância entre esses lugares são "espaços" Em linguagem de rede, lugares são nós ou vértices, enquanto espaços são elos ou limites. Lugares e espaços podem ser tanto entidades efetivas, físicas - jardins de palácios, estradas, casas - como podem ser estruturas cognitivas - laços de família, associações de clube, e muitos outros. Em ambos os casos, os lugares definidos pelo homem e os espaços "espacialmente" representados, tem-se uma paisagem sóciofísica conscientemente criada. A espacialidade, conseqüentemente, não é um fenômeno que ocorre naturalmente, ou um lugar onde uma cultura vive. Pelo contrário, é uma "objetividade constituída, uma realidade "viva"' (Soja 1989: 79). A espacialidade é, finalmente, "a respeito da ordenação das relações entre as pessoas", em um espaço e em um lugar (Hillier e Hanson 1984: 2).

A espacialidade pode ser a expressão da ideologia impressa na superfície da terra, mostrando que os humanos "não são tão conscientes de si mesmos quanto conscientes de si e para além de si" (Carrithers 1992: 60). O que isso significa é que a construção das paisagens modernas é uma função das redes de relação que as pessoas mantêm tanto entre si mesmas quanto com o meio ambiente que as circunda. Ao construir estas paisagens, homens e mulheres não são apenas agentes de sua cultura, eles são conscientes de si e para além de si. Homens e mulheres criam relações sociais e ambientais, dentro de uma complexa série de redes interligadas, cada uma das quais com um significado histórico específico. Por isso, somada à idéia de que es- 
ORSER Jr., C.E. A teoria de rede e a Arqueologia da História Moderna. Rev. do Museu de Arqueologia e Etnologia, São Paulo, Suplemento 3: 87-101, 1999.

tradas antigas e vias de transporte eram "laços que uniam" (Hassig 1991), podemos também dizer que ligações sociais representadas por estradas também unem homens e mulheres entre si. Os laços sociais e os elos físicos trabalham em conjunto.

\section{Princípios básicos da análise de rede para a Arqueologia Histórica}

Acadêmicos de várias disciplinas já há muitos anos têm dirigido análises de rede, mas os àrqueólogos, em larga medida, têm relutado em seguir os mesmos passos. Embora várias razões possam ser relacionadas para explicar o desinteresse geral dos arqueólogos pela análise de rede - algumas das quais seriam, possivelmente, puramente pessoais - duas, ao menos, surgem imediatamente à mente. Em primeiro lugar, os arqueólogos que estudam a Pré-História são usualmente relutantes, frequientemente por boas razões, em adotar métodos de pesquisa e abordagens que tenham sido originalmente desenvolvidos para interpretar cenários modernos. Muitos arqueólogos podem considerar que as grandes distâncias temporais que usualmente separam o objeto de seu estudo do objeto do modelo enfraqueça, de algum modo, sua aplicabilidade. Por exemplo, alguns arqueólogos são relutantes em usar informações a respeito do sistema ferroviário da Nova Inglaterra do século XIX em seus estudos dos sistemas viários da porção oeste da antiga América do Sul. Estabelecer a relevância dessa analogia pode ser extremamente difícil, e os pré-historiadores, logicamente, estão cientes dos problemas envolvidos nesse caso específico. De certa maneira, é essa compreensão que leva Clarke (1977b: 28) a argumentar que "a Arqueologia deve desenvolver seu próprio campo específico de teoria espacial": articulando-se, então, com outras disciplinas no exame do uso do espaço.

A segunda razão para que os Arqueólogos tenham amplamente rejeitado a análise de rede em suas pesquisas, pode ter suas origens em considerações práticas relacionadas com a coleta de dados. Posto de maneira simples, a coleta de informação mais adequada é, na maioria das vezes, irreal, ou mesmo impossível, quando se tem como pretenso foco de estudo redes de larga escala (Gorenflo e Bell 1991: 80). Os arqueólogos, não poucas vezes deparando com prazos e financiamentos diminutos, não podem, habitualmente, dar-se ao luxo de coletar dados em extensas regiões, pois tal coleta tomaria vários anos de pesquisa. Como um exemplo, o estudo de Struever da Esfera de Interação Hopewell, citado acima, só foi possível depois de ter sido precedido por, pelo menos, duas décadas de um sério trabalho arqueológico. Os arqueólogos têm sempre deparado com problemas referentes a uma adequada coleta de dados e tal problema tem sérias implicações para análise de rede, mesmo que tal análise seja conduzida por antropólogos culturais (Sanjek 1996: 397). O problema se torna mais grave quando os arqueólogos passam a pensar em termos transregionais ou globais. O geógrafo Peter Haggett (1990: 28) atenua o problema quando argumenta que o "problema colocado por qualquer assunto que objetiva ser global é simples e imediato: a superfície da terra é incomensuravelmente grande"

O interesse dos arqueólogos para com uma coleta de informação adequada e com a aplicação de modelos apropriados é, obviamente, importante de se considerar. Mas, embora essas questões justificadamente preocupem os pré-historiadores, elas não são de igual importância para o campo da Arqueologia Histórica. A presença do registro escrito, e de outras fontes de informação oral ou escrita, torna a análise de rede consideravelmente mais interessante para os estudiosos da Arqueologia Histórica. A presença de documentação textual, que pode incluir mapas, esboços, plantas e descrições escritas e verbais, pode mesmo diminuir a necessidade de se levar a termo levantamentos de campo de larga escala. Todo estudioso da Arqueologia Histórica sabe que o registro escrito não pode ser usado de maneira acrítica - mesmo em contextos onde aspectos materiais são levados em consideração. Entretanto, a maioria dos estudiosos concordaria que tais materiais podem ser excelentes fontes de informação. Na realidade, a presença de informação textual tem, frequientemente, sido usada como uma característica definidora da Arqueologia Histórica. Uma das grandes vantagens de se usar informação textual e verbal na Arqueologia Histórica é que, onde os pesquisadores têm usado tais informações para construir modelos de ocupação, elas fornecem, freqüentemente, correlações ponto a ponto entre o modelo e a entidade arqueológica em estudo. Mesmo em casos onde a associação direta não ocorre, é possível, com freqüência, alguma confiança justificável na aplicabilidade do modelo, graças à similaridade, ao longo do tem- 
po, entre o modelo e a unidade de estudo. Desta maneira, um modelo geográfico de uma ocupação do século XIX, em Maine, baseada em registros escritos e levantamento de campo, pode ser aplicado em um estudo arqueológico de uma ocupação do mesmo século, em Massachusetts.

Sem dúvida, as vantagens proporcionadas pela presença de informação textual dá uma enorme potencialidade à aplicação da análise de rede na Arqueologia Histórica. Documentos, cuidadosamente apreciados e avaliados, podem incrementar a validade e o poder de uma interpretação arqueológica, compreendida em um contexto espacial. Para além desta simples preocupação de caráter prático, entretanto, a análise de rede na Arqueologia Histórica é mesmo mais relevante por fornecer uma fundamentação empírica para questões que interessam hoje a muitos antropólogos e arqueólogos: "contextos estratigráficos, vozes múltiplas e processos históricos" (Houseman 1997: 753). Neste sentido, a aplicação da análise de rede para a Arqueologia, e particularmente para a Arqueologia Histórica, é oportuna e relevante.

A análise de rede começa com a simples noção, citada acima, de que homens e mulheres criam e mantêm relacionamentos. Tais redes de interação ou de associação existem porque indivíduos têm diversos relacionamentos. Estes relacionamentos podem tomar a forma de conexões "verticais" e "horizontais" (Schweizer 1997: 740). Conexões verticais são aquelas de caráter hierárquico, relacionadas com unidades sociais de tamanho cada vez maior. Conexões horizontais, por outro lado, são aquelas relacionadas com a interligação entre vários domínios dentro de uma unidade social.

É importante levar em consideração tanto os elos horizontais quanto os verticais, mas um interesse em elos hierárquicos é de extrema pertinência para um estudo de Arqueologia Histórica, pois tais conexões verticais conectam homens e mulheres a uma série de redes, do mesmo tipo das que entraram em operação em 1492 (e que ainda operam): redes inter-regionais, extra-regionais e mesmo transnacionais. Dada a natureza dessas conexões, os estudiosos da Arqueologia Histórica devem adotar, em suas análises, uma abordagem multiescalar. Uma perspectiva multiescalar é também necessária para se examinar as conexões horizontais, pois que tais conexões conectam entre si elementos políticos, econômicos, sociais, comunicativos, dentre outros de um corpo social.
Um modelo de rede e uma análise multiescalar caminham de mãos dadas. No decurso de suas vidas cotidianas, homens e mulheres conduzem suas ações ao longo de um número de diferentes escalas e dentro de um diverso número de redes. Para além do infinito número de escalas que podem existir em qualquer entidade social, indivíduos "compreendem padrões, reconhecem homogeneidade, planejam seu futuro e operam na presença de escalas específicas" (Marquardt 1992: 107; vide também Marquardt 1985). Uma "escala efetiva", a partir da qual um padrão ou um significado pode ser discernido, existe para cada decisão consciente feita por um indivíduo (Crumley 1979: 166).

Ao conduzir uma análise multiescalar aberta, o pesquisador parte de uma escala efetiva e busca compreendê-la. Uma vez que tal análise seja satisfatoriamente completada, o conhecimento é superado assim que $o$ analista se move em direção a outra escala. Este processo é repetido até que o investigador esteja satisfeito de que todas as possibilidades tenham sido exauridas. Assim, quando um investigador se move de uma escala para outra, tornase, com frequiência, claro que as entidades sociais sobre investigação mantêm suas conexões ao longo do tempo e do espaço. Os estudiosos da Arqueologia Histórica, ao examinarem o mundo moderno, devem compreender que os agentes do colonialismo, do capitalismo, da globalização e do eurocentrismo criam elos que trespassam várias escalas efetivas, tanto sociais quanto físicas.

A análise de rede dá preponderância inicial para pessoas, compreendendo-as como nós, e lugares, compreendendo-os, respectivamente, como os elos que conectam tais nós entre si. A análise de rede resultante, que indubitavelmente deve ser multiescalar, pode ser usada para modelar relacionamentos entre pessoas e pessoas, pessoas e lugares, lugares e lugares em dimensões tanto sincrônicas quanto diacrônicas.

Vários conceitos-chave repousam no cerne de uma análise de rede formal. Em uma análise de rede social, estes conceitos são, em uma ordem ascendente: ator, elode relacional, díade, tríade, subgrupo, grupo, relação e rede social (Wasserman e Faust 1994: 17-20). Em uma análise arqueológica, modelada a partir de uma análise de rede social, os conceitos analíticos devem ser: sítio, conector, díade, tríade, área, região, relação e rede (vide Tabela 1).

Em uma análise de rede social, os atores são indivíduos distintos ou unidades sociais que tra- 
ORSER Jr., C.E. A teoria de rede e a Arqueologia da História Moderna. Rev. do Museu de Arqueologia e Etnologia, São Paulo, Suplemento 3: 87-101, 1999.

Tabela 1

\begin{tabular}{lc}
\hline \multicolumn{2}{c}{ Conceitos centrais da análise de rede } \\
\hline \hline Social & Arqueológica \\
\hline ator & sítio \\
elo relacional & conector \\
díade & díade \\
tríade & tríade \\
subgrupo & área \\
grupo & região \\
relação & relação \\
rede social & rede física \\
\hline
\end{tabular}

balham coletivamente. Dependendo da escala de análise, os indivíduos podem ser homens e mulheres singulares em um grupo ou nação-estado, dentro de uma rede mundial. Para a análise arqueológica, entretanto, é mais apropriado considerar os atores como sendo homens e mulheres individuais, desde que essa concepção seja consistente com a noção geográfica de sítio. Embora possa ser difícil ou impossível conduzir uma pesquisa a respeito de homens e mulheres individuais em um cenário préhistórico, este ponto não precisa causar nenhum tormento para a Arqueologia Histórica, graças ao suporte da documentação não-arqueológica.

Os atores estão ligados entre si por laços de relação. Estas conexões sociais podem estar enraizadas em avaliações pessoais (tais como amizade, respeito ou sentimento de empatia), em uma associação ou afiliação (através da divisão do trabalho, de associações de grupo), em laços de família (reais ou efetivos) ou através de relações de poder (entre proprietário e trabalhador, legislador e legislado). Em um sentido geográfico, os laços de relação podem ser elementos físicos reais que ligam sítios entre si: rios, estradas, barragens e pontes. A importância de tais elementos na análise arqueológica é "que eles podem fornecer evidências tangíveis dos elos culturais existentes ao longo do espaço geográfico" (Trombold 1991: 8); tais elementos são, em sua essência, conectores. Uma díade, em um espaço tanto social quanto físico, refere-se a um relacionamento estabelecido entre dois atores ou sítios. Em uma análise de rede, o laço entre as duas entidades é percebida como uma propriedade integral do par ao invés de ser percebida como uma característica de cada elemento individual (Wasserman e Faust 1994: 18). Desta maneira, o laço entre pai e filho é uma propriedade de ambos os indivíduos, a um só tempo, assim como uma estrada que liga dois sítios origina-se em ambos os lugares a uma só vez. Em uma análise social, é possível, entretanto, ter "díades assimétricas" (Wasserman e Faust 1994: 510-1), onde um relacionamento é escolhido apenas por um dos indivíduos. Como um exemplo, um filho que se sente abandonado pode rejeitar um relacionamento promovido por seu pai. Díades assimétricas também podem aparecer em uma paisagem, embora provavelmente com menor freqüência. Um rio de corredeiras, ligando duas aldeias, dá-nos um exemplo. Na falta de barcos a motor, apenas os aldeões que vivem rio acima podem usar o rio como um elo de ligação. Os aldeões que vivem corredeira abaixo terão de usar outro elo de ligação (uma estrada ou uma trilha) se quiserem interagir com aqueles que vivem rio acima. A tríade, como a díade, tem sido o objeto de muitas análises de rede. Ela consiste, como o nome indica, de três atores, ou, pensando arqueologicamente, de três sítios interligados. Seguindo a mesma linha de raciocínio, um subgrupo, em uma análise de rede social, é composto de grupos de díades e tríades. Para a análise arqueológica, escolhi denominar o subgrupo de "área" e o grupo - composto de vários subgrupos - de "região" Este uso é consistente com a noção de região em uma análise de rede geográfica, compreendendo-a como uma área relacional definida por elos ou limites (Haggett e Chorley 1969: 5).

Em outro lugar (Orser 1996: 131-44) explorei o problema imposto pelos limites físicos ao se usar uma abordagem de rede em Arqueologia. Parafraseando a mim mesmo, argumentei que, quando os arqueólogos, explicitamente, pensam em elos de relação entre lugares e pessoas, podem ser forçados a esquecer sua compreensão tradicional do que constitui uma área ou região arqueológica. Em concordância com a proposição de que sítios de díades e de tríades são distinguidos por suas conexões, argumentei que os estudiosos da Arqueologia Histórica podem estar aptos a considerar partes de diferentes continentes dentro da mesma área ou região. Desta maneira, por um certo período de tempo, pode-se argumentar que o reino colonizador de Portu- 
gal e o Brasil colonial, ou o reino colonizador da Inglaterra e a África do Sul colonial, eram parte da mesma área ou região por causa de seus elos de ligação. Essa compreensão é completamente distinta daquela proposta pela paisagem cultural, onde o que conecta áreas umas com as outras são os processos cognitivos e culturais impostos pelos colonizadores.

\section{Um breve exemplo}

Dados os detalhes requeridos em uma rigorosa análise de rede multiescalar, muito mais espaço seria necessário para que se apresentasse, aqui, um exemplo completo. Todavia, é ainda importante fornecer um breve exemplo específico demonstrando o potencial interpretativo da análise de rede na Arqueologia. Limitações de espaço proíbem um exemplo completo, por isso meu exemplo será necessariamente insuficiente e esquemático. Mas, para demonstrar o valor da análise de rede, determe-ei em um exemplo do século XVII: o reino de Palmares, no nordeste do Brasil. Como eu já apontei em outro lugar (Orser 1994b, 1996), Palmares fornece um excelente estudo de caso para uma análise de rede arqueologicamente informada.

Palmares foi um reino construído no atual estado de Alagoas, no nordeste do Brasil, por um número de escravos fugitivos, por volta do ano 1605. O reino de Portugal destruiu a ocupação em 1694, mas, em seu acme, supõe-se que Palmares tenha tido por volta de 20.000 habitantes. Em 1992 e 1993, colaborei em um estudo de exploração arqueológica em Palmares, com Pedro Paulo A. Funari, e informação adicional a respeito deste esforço de pesquisa pode ser encontrada em outras publicações (Funari 1995a, 1995b, 1996a, 1996b; Orser 1992, 1993, 1994a, 1994b, 1998a; Orser e Funari 1992).

Palmares foi um reino unificado que visava resistir à escravidão e à degradação humana. No acme de seu desenvolvimento, Palmares era composto por dez vilas singulares: Amaro, Arotirene, Tabocas (duas vilas), Zumbi, Aqualtene, Dambrabanga, Subupira, Macaco e Andalaquituche, sendo Macaco o lugar onde vivia o rei (vide Mapa ). A pesquisa não está suficientemente avançada para indicar precisamente como as vilas individuais estavam conectadas entre si. Os registros históricos, entretanto, mostram claramente que os palmarinos mantinham contínuas relações com seu meioambiente. Um observador, que conheceu as con- dições do território de Palmares nos anos de 1670, descreveu-o como "um lugar naturalmente rude, montanhoso e seco, coberto com toda a variedade de árvores, conhecidas e desconhecidas" (Drummond 1859: 304). A densa floresta e as montanhas ao redor ajudaram a criar Palmares, da mesma maneira que tais características ajudaram a esconder e proteger os palmarinos dos exércitos da colônia, que buscavam invadir o reino a partir da costa. Ao mesmo tempo, o meio ambiente sustentava a população de Palmares. Documentos históricos deixam bastante claro que os habitantes criavam uma variedade de grãos, pescavam, e domesticavam aves selvagens. Usavam a vegetação para construir suas casas, para confeccionar cestas e erguer suas barricadas, assim como se serviam da argila local para produzir cerâmica. É inquestionável que os palmarinos criaram e mantiveram uma rede comple$x a$ de relacionamentos com seu meio-ambiente.

Uma série de complexas redes sociais e de poder contribuíram para manter unido o reino. $\mathrm{O}$ rei de Palmares era um homem chamado Ganga Zumba, e seu irmão, Gana Zona, governava a segunda cidade do reino. Uma das cidades era governada pelo sobrinho do rei, outra delas era governada por sua mãe. Zumbi, o último grande rei de Palmares, era o sobrinho do rei. Sem dúvida, laços de família e relações de poder - agindo como uma série de díades e tríades interrelacionadas - ajudaram a manter unido o reino, mesmo face a um ataque armado. Esta complexa série de confederações e relações tributárias ajudaram a definir Palmares tanto interna quanto externamente (Anderson 1996).

Seria relativamente fácil argumentar que estes relacionamentos, naturalmente, constituíam expressões culturais. $\mathrm{O}$ que todas as evidências disponíveis indicam é que os palmarinos ocupavamse com a construção de uma nova cultura no Novo Mundo. Mas mesmo esta compreensão permite a presença de duas escalas efetivas: as vilas individuais e o reino em si. Apenas quando combinamos uma perspectiva multiescalar com uma abordagem de rede é que podemos ver outras escalas efetivas. Por exemplo, dentro do reino em si existe uma severa divisão entre aqueles palmarinos que buscaram conciliação com os portugueses e aqueles que desejavam uma constante e contínua resistência armada. Este conflito foi o que, no final das contas, levou Zumbi a assassinar o rei, seu tio, e a assumir as rédeas do reino. De maneira similar, existiu um cisma entre os colonos portugueses, pois alguns deles, 
ORSER Jr., C.E. A teoria de rede e a Arqueologia da História Moderna. Rev. do Museu de Arqueologia e Etnologia, São Paulo, Suplemento 3: 87-101, 1999.

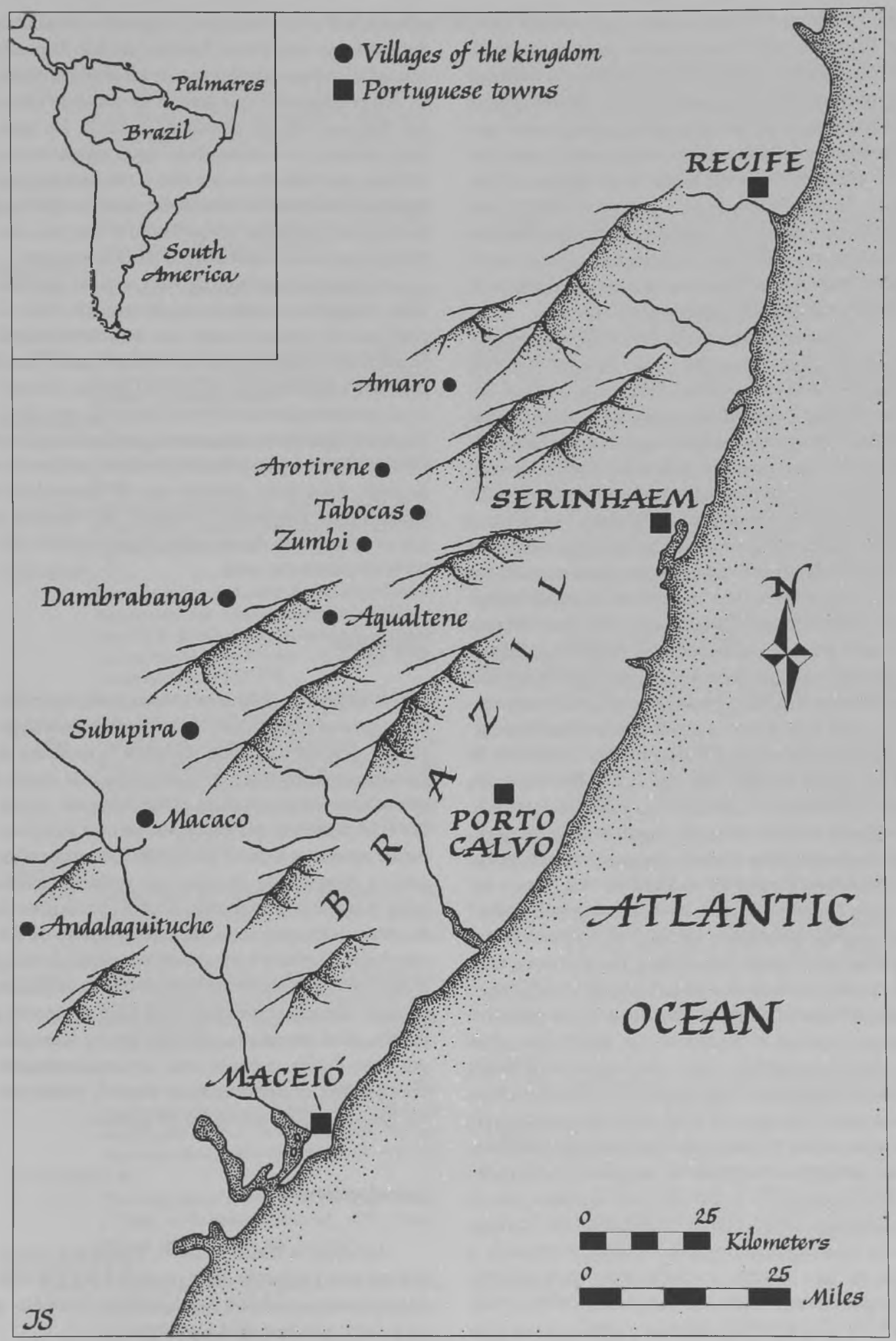


que viviam na fronteira colonial, optaram por apoiar Palmares contra seu próprio governo colonial. Desta maneira, tanto na região externa à fronteira do reino de Palmares quanto em seu interior, várias relações de poder foram constantemente sendo instituídas e redefinidas. Obviamente, uma compreensão plena de Palmares requer mais do que o simples conhecimento de uma cultura sincrética que fugitivos e fugitivas construíram entre as palmeiras do nordeste do Brasil. Uma compreensão mais completa pode ser obtida ao se adotar um modelo de rede explicitamente relacional (relational).

Ao incrementar a escala de análise torna-se possível que outras questões - que, de outra maneira, não seriam tão obviamente formuladas - sejam feitas: Por que os holandeses atacaram Palmares durante os anos em que estiveram no nordeste do Brasil? A resposta a esta questão pode parecer, à primeira vista, fácil demais de ser encontrada. Caspar Barleus (1923: 315), um contemporâneo de Palmares, descreveu o povo que lá vivia como um "grupo de assaltantes e escravos fugitivos". Barleus não estava sozinho em sua visão de Palmares; muitos dos inimigos coloniais dos palmarinos descreviam o reino nos mesmos termos. Para eles, os homens e as mulheres de Palmares eram simplesmente ladrões que roubavam suas plantações costeiras. Tendo ciência de tal perspectiva, seria lógico que os colonos holandeses buscassem destruir o reino de Palmares. Mas, teria isso, de fato, algum sentido, uma vez que compreendemos que a Holanda e os portugueses eram, na realidade, inimigos mortais em terras brasileiras? Cada superpotência buscava controlar a população e as riquezas nativas dessa parte da América do Sul. Tendo em mente o modelo de rede, devemos perguntar porque os colonos holandeses, inimigos dos colonos portugueses, não criaram um aliança com Palmares, também estes inimigos dos colonos portugueses? O mero ato de fazer tal pergunta leva-nos a outras questões: acaso estavam os holandeses tão apavorados pelas ações dos palmarinos contra outra nação européia que buscaram destruí-los em nome de uma solidariedade européia? Ou eram os holandeses tão racistas que simplesmente buscaram destruir um grupo de africanos renegados? Supondo um modelo de rede, podemos imaginar se acaso eram as ligações que os palmarinos tinham feito com os nativos da América, com os colonos portugueses, e entre si mesmos, o que de fato ofendia aos holandeses (para maiores detalhes dessas conexões, vide Orser 1994b, 1996: 41-53). Esta rede multifacetada e interligada de rela- ções era um sério obstáculo à expansão colonialista holandesa no interior da América do Sul. Supondo que os holandeses acreditavam poder arrebatar o Brasil dos portugueses, eles podem ter decidido remover Palmares em um momento propício. De qualquer maneira, se os holandeses eram simplesmente racistas, teria sido óbvio que eles se unissem aos portugueses para destruir Palmares e, uma vez que essa tarefa fosse concluída, começassem a lutar pelo império, opondo-se a seus antigos aliados europeus.

A história e a cultura de Palmares foi, sem dúvida, complexa, e serão necessários ainda mais alguns anos de pesquisa antes que uma nova e significativa reavaliação possa ser completada. Nossa pesquisa arqueológica inicial tem apenas fornecido a compreensão mais breve do que é, sem dúvida, uma história extremamente profunda e plena de significados. A aplicação de uma perspectiva de rede, entretanto, permite que os arqueólogos façam novas perguntas a respeito de Palmares e que se aproximem de um velho tópico de uma maneira inteiramente nova.

\section{Conclusão}

A análise de rede abre estimulantes oportunidades para os arqueólogos, especialmente para aqueles que estudam a História Moderna. A presença de documentação escrita e de testemunho oral implica que os arqueólogos podem, potencialmente, aprender - de maneiras que não poderiam ser imediatamente aparentes a partir dos depósitos arqueológi$\cos -\mathbf{a}$ respeito das ligações que mantêm ligados entre si homens e mulheres. As reais vantagens de se usar a análise de rede, em uma pesquisa de Arqueologia Histórica e a partir de um estudo de larga escala, devem ainda de ser demonstradas. A análise de rede, quando combinada com uma perspectiva multiescalar, entretanto, permite que os arqueólogos tanto façam, como já dito, novas e interessantes questões, quanto forneçam novas e fundamentais interpretações a respeito do passado.

\section{Agradecimentos}

Agradeço a Pedro Paulo A. Funari por convidar-me para participar desta reunião e por seu contínuo apoio e colaboração. Agradeço, também, a Jack Scott por desenhar a gravura. 
ORSER Jr., C.E. A teoria de rede e a Arqueologia da História Modema. Rev. do Museu de Arqueologia e Etnologia, São Paulo, Suplemento 3: 87-101, 1999.

\section{Referências bibliográficas}

ANDERSON, R.N.

1996 The Quilombo of Palmares: A New Overview of a Maroon State in Seventeenth-Century Brazil. Journal of Latin American Studies, 28: $545-566$.

BARLEUS, $\mathrm{C}$.

1923 Nederlandsch Brazilie Onder Het Bewind von Johan Maurits, Grave van Nassau, 1637-1644. Gravenhage: Martinus Nijhoff.

BARNES, J.A.

1954 Class and Committees in a Norwegian Island Parish. Human Relations, 7: 39-54.

CARRITHERS, $M$.

1992 Why Humans Have Cultures: Explaining Anthropology and Social Diversity. Oxford: Oxford University Press.

CLARKE, D.L.

1968 Analytical Archaeology. London: Methuen.

1977a (Ed.) Spatial Archaeology. London: Academic Press.

1977b Spatial Information in Archaeology. D.L. Clarke (Ed.) Spatial Archaeology. London, Academic Press: 1-32.

\section{CRUMLEY, C.L.}

1979 Three Locational Models: An Epistemological Assessment for Anthropology and Archaeology. M.B. Schiffer (Ed.) Advances in Archaeological Method and Theory, vol. 2. New York, Academic Press:141-173.

DE CUNZO, L.A.; O'MALLEY, T.; LEWIS, M.J.; THOMAS, G.E.; WILMANNS-WELLS, C.

1996 Father Rapp's Garden at Economy: Harmony Society Culture in Microcosm. R. Yamin; K.B. Metheny (Eds.) Landscape Archaeology: Reading and Interpreting the American Historical Landscape. Knoxville, University of Tennessee Press: 91-117.

DEETZ, J.

1990 Landscapes as Cultural Statements. W.M. Kelso; R. Most (Eds.) Earth Patterns: Essays in Landscape Archaeology. Charlottesville, University Press of Virginia:1-14.

1991 Archaeological Evidence of Sixteenth- and Seventeenth-Century Encounters. L. Falk (Ed.) Historical Archaeology in Global Perspective. Washing-

DRUMMOND, C. ton D.C., Smithsonian Institution Press: 1-19.

1859 Relação das guerras feitas aos Palmares de Pernambuco no tempo de Governador D. Pedro de Almeida de 1675 a 1678 . Revista do Instituto Histórico e Gragráfico Brasileiro, 22: 303-329.

DURKHEIM, E.

1915. The Elementary Forms of the Religious Life: A Study in Religious Sociology. J.W. Swain, trans. London: Allen and Unwin.

FUNARI, P.P.A.

1995a A cultura material de Palmares: o escudo das relações socials de um quilombo pela arqueologia. Idéias: 37-42. 1995b A "repúplica de Palmares" e a arqueologia da Serra da Barriga. Revista USP, 28: 6-13.

1996a Novas perspectives abertas pela arqueologia na Serra da Barriga. L.M. Schwarcz; L.V. de S. Reis (Eds.) Negras Imagens. São Paulo, Editoria da Universidade de São Paulo: 139230.

1996b A arqueologia de Palmares: sua contribuição para o conhecimento da história da cultura afro-americana. J.J. Reis; F. dos Santos Gomes (Eds.) Liberdade por um fio: história dos quilombos no Brasil. São Paulo, Editoria Schwarcz: 26-51.

HAGGETT, $P$.

1990 The Geographer's Art. Oxford: Basil Blackwell.

HAGGETT, P.; CHORLEY, R.J.

1969 Network Analysis in Geography. New York: St. Martin's Press.

HASSIG, R.

1991 Roads, Routes, and Ties that Bind. C.D. Trombold (Ed.) Ancient Road Networks and Settlement Hierarchies in the New World. Cambridge, Cambridge University Press: 17-27.

HILLIER, B.; HANSON, J.

1984 The Social Logic of Space. Cambridge: Cambridge University Press.

HODDER, I.; ORTON, C.

1976 Spatial Analysis in Archaeology. Cambridge: Cambridge University Press.

HOUSEMAN, M.

1997 Comment on Thomas Schweizer's "Embeddedness of Ethnographic Cases: A Social Networks Perspective" Current Anthropology, 38: 753-754.

KELSO, W. M.; MOST, R. (Eds.)

1990 Earth Patterns: Essays in Landscape Archaeolo$g y$. Charlottesville, University Press of Virginia.

KENT, $\mathrm{S}$.

1984 Analyzing Activity Areas: An Ethnoarchaeological Study of the Use of Space. Albuquerque: University of New Mexico Press.

KNOKE, D.; KUKLINSKI, J.H.

19882 Network Analysis. Newberry Park, California: Sage.

LEONE, M.P.

1995 A Historical Archaeology of Capitalism. American Anthropologist, 97: 251-268.

LEONE, M.P.; STABLER, J.; BURLAGA, A.-M.

1998 A Street Plan for Hierarchy in Annapolis: An Analysis of State Circle as a Geometric Form. P.A. Shackel; P.R. Mullins; M.S. Warner (Eds.) Annapolis Pasts: Historical Archaeology in Annapolis, Maryland. Knoxville, University of Tennessee Press: 291-306.

LESSER, A.

1961 Social Fields and the Evolution of Society. Southwestern Journal of Anthropology, 17: 40-48. 
ORSER Jr., C.E. A teoria de rede e a Arqueologia da História Moderna. Rev. do Museu de Arqueologia e Etnologia, São Paulo, Suplemento 3: 87-101, 1999.

MANDER, J.

1996 Facing the Rising Tide. J. Mander; E. Goldsmith (Eds.) The Case Against the Global Economy and For a Turn Toward the Local. San Francisco, Sierra Club Books: 3-19.

MARQUARDT, W.H

1985 Complexity and Scale in the Study of FisherGatherer-Hunters: An Example from the Eastern United States. T.D. Price; J.A. Brown (Eds.) Prehistoric Hunter-Gatherers: The Emergence of Cultural Complexity. Orlando, Academic Press: 59-98.

1992 Dialectical Archaeology. M.B. Schiffer (Ed.) Archaeological Method and Theory, vol. 4. Tucson, University of Arizona Press: 101-140.

MATTHEWS, C.N

1998 Part of a "Polished Society": Style and Ideology in Annapolis's Georgian Architecture. P.A. Shackel; P.R. Mullins; M.S. Warner (Eds.) Annapolis Pasts: Historical Archaeology in Annapolis, Maryland. Knoxville, University of Tennessee Press: 244-267.

MILANICH, J.T.

1998 Case of the Missing Moat. Archaeology, 51(5): 58.

MITCHELL, J.C.

1974 Social Networks. Annual Reviews of Anthropology, 3: 279-299.

ORSER Jr., C.E.

1992 Search of Zumbi: Preliminary Archaeological Research at the Serra da Barriga, State of Alagoas, Brazil. Prepared for the National Geographic Society, Washington, D.C.

1993 In Search of Zumbi: 1993 Season. Prepared for the National Geographic Society, Washington, D.C., and the Social Science Research Council, New York.

1994a Searching for Palmares at the Serra da Barriga, Brazil. National Geographic Research and Exploration, 10: 480-482.

1994b Toward a Global Historical Archaeology: An Example from Brazil. Historical Archaeology, 28(1): 1-18.

1996 A Historical Archaeology of the Modern World. New York: Plenum Press.

1998a Archaeology of the African Diaspora. Annual Reviews of Anthropology, 27: 63-82.

1998b Epilogue: From Georgian Order to Social Relations at Annapolis and Beyond. P.A. Shackel; P.R. Mullins; M.S. Warner (Eds.) Annapolis Pasts: Historical Archaeology in Annapolis, Maryland. Knoxville, University of Tennessee Press: 307-324.

1998c Negotiating our "Familiar Pasts." S. Tarlow; S. West (Eds.) The Familiar Past? Archaeologies of Britain, 1550-1950. London, Routledge: 273-285.

ORSER Jr., C.E.; FUNARI, P.P.A.

1992 Pesquisa arqueológica inicial em Palmares. Estudos Ibero-Americanos 18: 53-69.
RABINOW, P. (Ed.)

1984 The Foucault Reader. New York: Pantheon.

RADCLIFFE-BROWN, A.R.

1940 On Social Structure. Journal of the Royal Anthropological Society of Great Britain and Ireland, 70: 1-12.

SANJEK, R.

1996 Network Analysis. A. Barnard; J. Spencer (Eds.) Encyclopedia of Social and Cultural Anthropology. London, Routledge: 396-397.

SCOTT, A.J.

1998 Regions and the World Economy: The Coming Shape of Global Production, Competition, and Political Order. Oxford: Oxford University Press.

SCHWEIZER, $T$.

1997 Embeddedness of Ethnographic Cases: A Social Networks Perspective. Current Anthropology, 38: 739-760.

SHACKEL, P.A.; MULLINS, P.R.; WARNER, M.S. (Eds.)

1998 Annapolis Pasts: Historical Archaeology in Annapolis, Maryland. Knoxville, University of Tennessee Press.

SHEPPARD, E.; BARNES, T.J.

1990 The Capitalist Space Economy: Geographical Analysis After Ricardo, Marx, and Sraffa. London: Unwin Hyman.

SOJA, E.W.

1989 Postmodern Geographies: The Reassertion of Space in Critical Social Theory. London: Verso.

\section{STRUEVER, $\mathrm{S}$.}

1964 The Hopewell Interaction Sphere in RiverineWestern Great Lakes Culture History. J.R. Caldwell; R.L. Hall (Eds.) Hopewellian Studies. Springfield, Illinois State Museum: 85-106.

STRUEVER, S.; HOUART, G.L.

1972 An Analysis of the Hopewell Interaction Sphere. E.N. Wilmsen (Ed.) Social Exchange and Interaction. Ann Arbor, Museum of Anthropology, University of Michigan: 47-79.

TROMBOLD, C.D.

1991 An Introduction to the Study of Ancient New World Road Networks. C.D. Trombold (Ed.) Ancient Road Networks and Settlement Hierarchies in the New World. Cambridge, Cambridge University Press: 1-9.

WARNER, M.S.

1998 "The Best There Is of Us": Ceramics and Status in African American Annapolis. P.A. Shackel; P.R. Mullins; M.S. Warner (Eds.) Annapolis Pasts: Historical Archaeology in Annapolis, Maryland. Knoxville, University of Tennessee Press: 190-212.

WASSERMAN, S.; FAUST, K.

1994 Social Network Analysis: Methods and Applications. Cambridge: Cambridge University Press.

WILLEY, G.R.

1953 Prehistoric Settlement Patterns in the Virú Valley, Perú. Smithsonian Institution, Bureau of American Ethnology Bulletin 153. Washington, D.C.: Government Printing Office. 
ORSER Jr., C.E. A teoria de rede e a Arqueologia da História Moderna. Rev. do Museu de Arqueologia e Etnologia, São Paulo, Suplemento 3: 87-101, 1999.

\section{WOLF, E.R.}

1982 Europe and the People without History. Berkeley: University of California Press.

1984 Culture: Panacea or Problem? American Antiquity, 49: 393-400.

YAMIN, R.; METHENY, K.B. (Eds.)

1996 Landscape Archaeology: Reading and Interpreting the American Historical Landscape. Knoxville: University of Tennessee Press.

\section{ZIMMERMAN, L.J.}

1977 Prehistoric Locational Behavior: A Computer Simulation. Report 10. Office of the State Archaeologist, University of Iowa, lowa City. 